\title{
Children's Clothing Virtual Simulation Immersive Design and Show Based on Machine Learning
}

\author{
Dai Jingyu $\mathbb{D}^{1},{ }^{1}$ Dai Hongyu, ${ }^{2}$ Wang Jianxing, ${ }^{3}$ and Wang Xuanzi ${ }^{4}$ \\ ${ }^{1}$ College of Art Design and Media, Sanda University, Shanghai 201209, China \\ ${ }^{2}$ Data Science Institute, Vanderbilt University, Nashville, TN 37235, USA \\ ${ }^{3}$ Chongqing Jiaotong University, Chongqing 400000, China \\ ${ }^{4}$ Hunan Institute of Technology, Hunan 421200, China \\ Correspondence should be addressed to Dai Jingyu; yjdai@sandau.edu.cn
}

Received 8 September 2021; Revised 9 October 2021; Accepted 21 October 2021; Published 8 November 2021

Academic Editor: omar cheikhrouhou

Copyright (C 2021 Dai Jingyu et al. This is an open access article distributed under the Creative Commons Attribution License, which permits unrestricted use, distribution, and reproduction in any medium, provided the original work is properly cited.

\begin{abstract}
In view of the inconvenient display of children's clothing, the poor experience of designers when modifying sample clothes, and the immature display of children's clothing, which affects the rational judgment of fashion buyers, this paper puts forward the modular design method of children's clothing virtual fitting. This research uses Lectra CAD software to make children's clothing pattern, Clo3D for virtual modular design, and "Insanda children's clothing virtual design and show" for virtual try-on and show. The simulation results show that the research can effectively improve the efficiency of designers and buyers, can save costs, and can be effectively applied in the commercial field. At the same time, it provides a practical basis for the development of children's clothing virtual display technology and the formulation of standards related to children's clothing in the future.
\end{abstract}

\section{Introduction}

Virtual reality (VR) technology, also known as virtual environment, spiritual environment, or artificial environment, refers to the technology of using computers to generate a virtual world that can directly exert visual, auditory, and tactile feelings on participants and allow them to observe and operate interactively. At present, virtual reality needs deep development in supporting technologies and application scenarios. Virtual display technology originated in the United States, and then it was popularized and developed in Japan, Switzerland, etc. Currently, virtual display technology is playing an important role in many fields such as military, education, scientific research, architecture, medical treatment, movies, and television [1]. Virtual display technology and customization technology, related to clothing, have made much progress at home and abroad $[2,3]$. MVM company has developed My Virtual Model fitting website. Besides, the "three-dimensional e-commerce center" project promoted by the London Institute of Technology and the " $M$ to $M 3 \mathrm{D}^{\prime \prime}$ project from European Association for
Information and Algorithm Research both have carried out relevant research on three-dimensional clothing virtual display technology [4-6].

For children's clothing design, there is a long existing problem. Due to the changeable moods of children, fitting and fashion shows are hard to be controlled. As a result, the design of children's clothing was more biased towards perceptual-cognitive aesthetics, and therefore lacked practical judgment. The positioning of professional models for children's clothing is vague, which also affects the professional judgment of children's clothing buyers. With the application of a series of virtual simulation software, the effect of ready-made clothes on children can be observed during garment cutting, and thus clothes can be modified and adjusted in time. However, the traditional software is only based for the design of adult clothing, and the virtual simulation on the basis of the characteristics of children's clothing is not mature. The basic characteristics of the VR system are three: immersion, interaction, and imagination. It emphasizes the leading role of people in the VR system, so as to make the information processing system suitable for 
people's needs and consistent with people's sensory feelings. VR systems are mainly divided into four categories: immersive, nonimmersive, distributed, and augmented reality.

According to the research on the current domestic clothing virtual simulation methods, this paper puts forward a new virtual simulation method for children's clothing. In addition, the research team, in cooperation with American fantasy engine company, developed a virtual simulation platform, "children's clothing show and design." The platform is based on machine learning and provides a solid foundation for further research on children's clothing virtual simulation. Note that virtual simulation, or simulation technology, is the technology that uses one system to imitate another real system. This virtual world is generated by computers, which can be the reproduction of the real world or the conceived world. Users can naturally interact with the virtual world with the help of various sensing channels such as vision, hearing, and touch. It creates a three-dimensional virtual world for users to reflect the change and interaction of solid objects in real time by means of simulation, and provides users with a three-dimensional interface for observing and interacting with the virtual world through helmet mounted display, data gloves, and other auxiliary sensing devices, so that users can directly participate in and explore the role and change of simulation objects in their environment and produce a sense of immersion.

\section{Literature Review}

2.1. Children's Clothing Design. Children's clothing has always been an important item in clothing products. According to the census data, there are about 200 million children under the age of 14 in China, accounting for $1 / 6$ of China's population. Among the children, the only child accounts for 34\% [7]. According to the trend evaluation and scientific prediction on other aspects, the authoritative institutions of China's garment industry predicted that children's clothing would increase at a rate of about $9 \%$. The quantity of children's clothing in China was only 800 million in 2000, but it was expected to exceed 1 billion in 2003. Besides, Children's clothing refers to clothing suitable for children. According to age, it covers baby clothes and middle and big children's clothes, etc. It also includes the campus clothing of primary and secondary schools. According to the type of clothes, they are divided into: one-piece clothes, coats, trousers, sweaters, suits, T-shirts, shoes, etc. The material requirements of children's clothes are higher than those of adults. They should be beautiful and comfortable. The key is to ensure the quality of children's clothes and not damage children's health.

"In fact, the idea of childhood as a social structure did not exist in the Middle Ages" [7]. Before the late 19th century, children's clothing in western countries was simply smaller versions of Yuan's adult clothing, which focused on practical functions [8]. It was not until the late 18 th century that Rousseau's article "discovering children" helped Europeans pay close attention to children. Therefore, the road to children's clothing design was opened up in the modern sense. At the beginning of the century, children's clothing moved towards the direction of "adult". The style of adult was popular, but there existed a lot of controversies.

At present, design colleges at home and abroad all set up children's clothing design majors (directions). On the talent training of children's clothing design, they mostly offered elective courses to encourage people to acquire knowledge through practice in enterprises. This way leads most fashion designers to get used to children's clothing design from the perspective of adult clothing design.

In terms of fabric testing for children, China has successively issued FZ/t81003-2003 "Children clothing and Student clothing," FZ/t73025-2013 "Infants knitting clothing," FZ/t81014-2008 "Infants clothing," and GB18401-2010 "National Fundamental Safety Technical Standard For Textiles." However, the study is still blank in the comfort of children's clothing. In this paper, the preset label based on machine learning is used as a training set, and then it is set to generate the algorithm, which will help to provide a database for the formulation of children's clothing comfort standard. Children's clothing can be divided into five stages, of which stages 1,2 , and 3 ( $0-6$ years old) are social members with high cognitive ability and healthy personality. The research object of this paper is designed for preschool children's clothing in stage 3 (4-6 years old) and school-age children's clothing in stage 4 (7-11 years old).

In addition, machine learning is a science of artificial intelligence. The main research object in this field is artificial intelligence, especially how to improve the performance of specific algorithms in empirical learning. Machine learning is the study of computer algorithms that can be automatically improved by experience. It is the use of data or past experience to optimize the performance standards of computer programs.

2.2. Machine Learning. With the application of machine learning in various fields, many achievements of realistic importance have been made in recent years. Autonomous learning system simulates human thinking by using machine learning, pattern recognition, and natural language processing, and trains a system or equipment through machinelearning algorithm. The purpose is to establish an automatic computer model that can solve problems without human participation. Machine learning is an interdisciplinary subject involving probability theory, statistics, approximation theory, convex analysis, algorithm complexity theory, and so on. It focuses on how computers simulate or realize human learning behavior, so as to obtain new knowledge or skills, reorganize the existing knowledge structure, and continuously improve its performance.

Machine learning is one of the branches of AI technology. According to the learning type, machine learning is divided into supervised learning, unsupervised learning, and reinforcement learning [9]. Reinforcement learning is regarded as a combination of supervised learning and unsupervised learning, which aims to maximize the accuracy of operation (Table 1). 
TABle 1: Characteristics and limitations of different machine learning.

\begin{tabular}{|c|c|c|c|}
\hline Type & Algorithm & Characteristics & Limitations \\
\hline \multirow{7}{*}{$\begin{array}{l}\text { Supervised } \\
\text { learning }\end{array}$} & Artificial neural network & $\begin{array}{c}\text { Applied to nonlinear relations, suitable for } \\
\text { various data types, and can be applied in deep } \\
\text { learning algorithms }\end{array}$ & $\begin{array}{l}\text { Data overfitting; long calculation time; } \\
\text { many parameters }\end{array}$ \\
\hline & Decision tree & $\begin{array}{l}\text { Apply "yes/no" to classify data for easy } \\
\text { implementation and understanding }\end{array}$ & Only for small datasets \\
\hline & Random forest & $\begin{array}{l}\text { Derivation of decision tree; fast training speed } \\
\text { and can handle high-dimensional data }\end{array}$ & $\begin{array}{l}\text { It can only be predicted within the data } \\
\text { range of the training set; otherwise, it is } \\
\text { easy to cause overfitting }\end{array}$ \\
\hline & $K$-nearest neighbor algorithm & $\begin{array}{l}\text { Nonparametric methods for classification and } \\
\text { regression problems }\end{array}$ & $\begin{array}{l}\text { Low efficiency, data prediction results } \\
\text { are not interpretable, and } \\
\text { dimensionality is disastrous }\end{array}$ \\
\hline & Naive Bayes classifier & Simple probabilistic classifier & $\begin{array}{c}\text { There are restrictions on the size of the } \\
\text { dataset }\end{array}$ \\
\hline & Fuzzy logic & Able to handle uncertain or imprecise data & Establishing fuzzy database is difficult \\
\hline & Support vector machine & $\begin{array}{l}\text { Less overfitting occurs and requires less storage } \\
\text { space }\end{array}$ & $\begin{array}{l}\text { High requirements for the selection of } \\
\text { core functions }\end{array}$ \\
\hline \multirow{2}{*}{$\begin{array}{l}\text { Unsupervised } \\
\text { learning }\end{array}$} & Clustering algorithm & $\begin{array}{l}\text { The process of classifying unlabeled data into } \\
\text { different classes or clusters }\end{array}$ & $\begin{array}{c}\text { It is difficult to identify the initial } \\
\text { clustering pattern, which is easy to } \\
\text { cause bias }\end{array}$ \\
\hline & Association rule algorithm & $\begin{array}{c}\text { Discover the association between data items in } \\
\text { a large dataset }\end{array}$ & $\begin{array}{l}\text { The database is scanned too many } \\
\text { times, and the importance of each } \\
\text { attribute is not considered }\end{array}$ \\
\hline Deep learning & $\begin{array}{l}\text { Cyclic neural network, } \\
\text { convolution neural network, } \\
\text { and depth neural network }\end{array}$ & $\begin{array}{l}\text { Multilayer ANN is used to simulate the } \\
\text { operation of human brain, and the prediction is } \\
\text { made automatically according to the input data }\end{array}$ & $\begin{array}{l}\text { Overfitting may lead to poor } \\
\text { prediction results and require a large } \\
\text { number of training datasets }\end{array}$ \\
\hline
\end{tabular}

Deep learning is a technology which can realize machine learning. It uses multilayer ANN to simulate the operation of human brain and automatically makes prediction according to the input data. Deep learning using ANN includes cyclic neural network, convolutional neural network and deep neural network. Based on the perspective of mechanical learning, this paper mainly uses the multi-label learning method in deep learning to develop the training set.

Moreover, unsupervised learning from the bottom up is to start from the bottom and train from layer to layer. It can be regarded as an unsupervised training process, which is the most different part from the traditional neural network, and can be regarded as a feature learning process. Specifically, the first layer is trained with uncalibrated data. During training, the parameters of the first layer are learned first. This layer can be regarded as the hidden layer of a three-layer neural network that minimizes the difference between output and input. Due to the limitation of model capacity and sparsity constraints, the obtained model can learn the structure of the data itself. Thus, features with more representation ability than input are obtained.

2.3. Immersive Virtual Simulation Design. Immersion theory holds that people are happiest in immersion, which can improve efficiency. Jaron Lanier proposed "virtual reality" in 1984. The development of computer graphics and virtual reality technology provided strong technical support for garment virtual simulation [10-12]. Specifically, garment $3 \mathrm{D}$ virtual modeling refers to the $3 \mathrm{D}$ modeling and virtual simulation of garment and cloth. The purpose is to establish the digital and visual model of clothing.
Meanwhile, the physical model, supporting the elastic and bending characteristics of flexible body, is established to simulate the drape effect of cloth; with the help of computers, the three-dimensional virtual human body model is established through the three-dimensional scanning technology [13]. On this basis, the corresponding threedimensional clothing piece model is constructed, and thereby the clothing can be dynamically displayed [14]. Real-time rendering and interaction, as the core of the virtual simulation system, have high requirements for the algorithm of rendering refresh process and the parallel processing mechanism of visual graphics. These requirements make the realism and immersion of the system possible [15]. At present, the widely used virtual simulation software for garment design in the industry is shown in Table 2. But, there is no targeted application module for children's clothing design and fashion show at home and abroad.

It should be noted that, immersion theory explains why people fully devote themselves to the situation, concentrate, filter out all irrelevant perceptions, and enter a state of immersion. The occurrence of immersion experience is accompanied by nine factors: clear goal, prompting feedback, balancing challenges, integrating consciousness, removing distractions, facing failure, finding selfconsciousness, saving time, and boosting action.

Fashion show refers to a stage form expressed by the model body, which facilitates fashion buyers to order and garment companies to promote products. To create the stage form, the stage director would process the sound and light. The research team of Beijing Institute of Clothing Technology [16] has developed and implemented a virtual 
TABLE 2: Clothing virtual simulation software widely used in the industry.

\begin{tabular}{|c|c|c|c|}
\hline $\begin{array}{l}\text { Software } \\
\text { name }\end{array}$ & Country & Characteristics & Shortcoming \\
\hline Dressing SIM & Japan & $\begin{array}{l}\text { Through the change of input parameters, demonstrate } \\
\text { the sewing display of garment template from } 2 \mathrm{D} \text { to } 3 \mathrm{D} \text {. }\end{array}$ & $\begin{array}{c}\text { Dressing SIM, whose interaction changes with input } \\
\text { parameters, is far from the mainstream mouse } \\
\text { selection type. }\end{array}$ \\
\hline Clo3D & Korea & $\begin{array}{l}\text { As the most integrated software in the industry, it is } \\
\text { easy to use and establish a precedent for garment } \\
\text { modular virtual simulation design. The biggest feature } \\
\text { is that it can intelligently set fabric properties after } \\
\text { scanning fabric. }\end{array}$ & $\begin{array}{l}\text { Rendering has high requirements for equipment. It } \\
\text { has less self-contained fabrics and does not support } \\
\text { designer cooperation platform. }\end{array}$ \\
\hline Vsticher & USA & $\begin{array}{l}\text { Geber's derivative application software, which focuses } \\
\text { on the three-dimensional fitting, can restore the } \\
\text { modeling characteristics and structural techniques of } \\
\text { three-dimensional cutting. }\end{array}$ & $\begin{array}{l}\text { As nongarment plane simulation software, it lacks } \\
\text { plane structure module. }\end{array}$ \\
\hline STYLE3D & China & $\begin{array}{l}\text { Some functions are similar to Clo3D. And, a designer } \\
\text { collaboration platform is developed to make the } \\
\text { material easier to share. }\end{array}$ & $\begin{array}{l}\text { Catwalk application is lacking and rendering is not } \\
\text { detailed enough. }\end{array}$ \\
\hline Optitex & Israel & $\begin{array}{l}\text { The software system of garment typesetting, biased } \\
\text { towards intelligent layout, can effectively help the } \\
\text { design and production of plane pattern. At the same } \\
\text { time, it can also help simple fitting. }\end{array}$ & $\begin{array}{l}\text { There are few application functions in the field of } \\
\text { virtual simulation fitting. }\end{array}$ \\
\hline $\begin{array}{l}\text { Marvelous } \\
\text { Designer }\end{array}$ & Korea & $\begin{array}{l}\text { From the same company as Clo3D, it is widely used in } \\
\text { role setting in games, and has a good restoration of } \\
\text { various properties and drape of fabrics. }\end{array}$ & $\begin{array}{l}\text { Clothing structure is unreal. The software has strong } \\
\text { game and animation attributes. }\end{array}$ \\
\hline $\begin{array}{l}\text { Assyst } \mathrm{GmbH} \\
\text { Vidya }\end{array}$ & Germany & $\begin{array}{l}\text { Combined with garment CAD pattern, digital } \\
\text { mannequin model, fabric material mechanics, and } 3 \mathrm{D} \\
\text { visual rendering technology, it realized the } 3 \mathrm{D} \\
\text { simulation and visualization of garment. }\end{array}$ & $\begin{array}{l}\text { The restoration of clothing details is not realistic } \\
\text { enough, and show scene display is lacking. }\end{array}$ \\
\hline Browzwear & Singapore & $\begin{array}{l}\text { The first virtual simulation application that can be } \\
\text { connected with VR. }\end{array}$ & $\begin{array}{l}\text { The software, whose function of rendering is weak, is } \\
\text { suitable for the output of style drawing rather than the } \\
\text { output of human trial. }\end{array}$ \\
\hline
\end{tabular}

garment show system based on Unity platform. Unity is a real-time $3 \mathrm{D}$ interactive content creation and operation platform. All creators, including game development, art, architecture, automobile design, film and television, turn creativity into reality with unity. Unity platform provides a complete set of software solutions that can be used to create, operate, and realize any real-time interactive $2 \mathrm{D}$ and $3 \mathrm{D}$ content. The supporting platforms include mobile phones, tablets, PCs, game consoles, augmented reality, and virtual reality devices. With the help of virtual reality technology, the system realized $360^{\circ}$ free perspective model and virtual clothing display. The digital performance and simulation laboratory of Beijing University of Technology has developed the "simulation arrangement system of square artistic performance" for the 2008 Olympic Games [17]. Nguyeny et al. [18] invented a technology that combined performance-based animation with physical model to preview the interaction of the final integrated scene online. In 1992, South Korea's Clo3D launched a three-dimensional clothing style design software, which can show the dynamic changes of clothing fabrics and reflect the quantity of space. At the same time, it can also set the background, simulation scene and light contrast to generate a virtual environment. In addition, the software can interact with people, modify parameters intuitively, and directly import and export the size of garment. The software is widely used in the field of fashion design, but it does not support children's clothing. In particular, its virtual show function is not suitable for children's clothing.

In summary, the technical means of using virtual reality to help fashion design has been available. However, the methods and platforms for children's clothing design in the industry are still blank from the perspective of ready-made clothes.

\section{Technical Route}

The embodiment of the invention provides a simulation method and platform for children's fashion show and design, which is based on machine learning. Figure 1 shows intangible cultural heritage with respect to the children's clothing works. As can be seen, children's virtual simulation clothing can mainly show the effect of children's wearing through design and show. And, the show route can be arranged with the help of interactive design tools. It can help designers observe the design quality and effect of children's clothing, and thus improve the design of children's clothing; the system automatically carries out algorithm training in the light of the designer's remark options. Finally, according to the characteristics of clothing styles, the system automatically predicts the shortcomings of styles and displays them in the form of reports. 


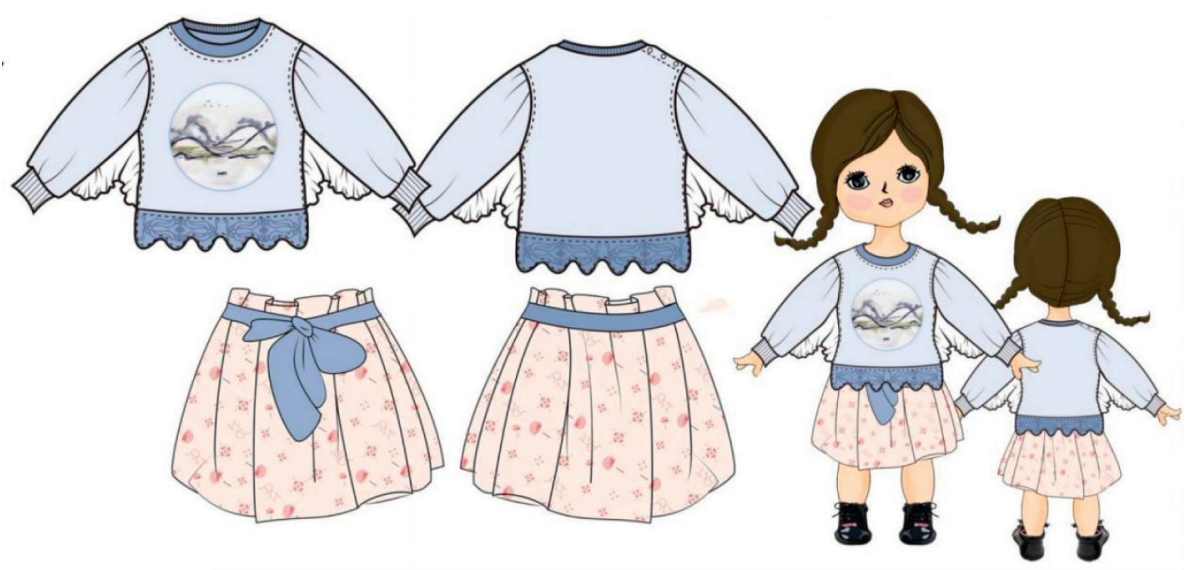

FIgURE 1: Painting, the bronze award of the French Saint Etienne design award.

The technical route is shown in Figure 2 and the route is mainly divided into three parts: plane plate making, virtual simulation design, and virtual simulation show. The plane plate making part is to complete the drawing of digital template on computer by using Lectra garment CAD; the virtual simulation design part is to carry out virtual stitching by importing the. DXF format file into CLO virtual simulation software and then showing the dressing effect of virtual models. At the same time, it can simply copy and upgrade children's clothing styles in order to meet the individualized custom requirements to a certain extent. Project files are generated and then imported into Insanda children's clothing virtual design and show virtual simulation software. Finally, they are displayed on different clothing T platforms in turns. While watching the children's clothing, the designer can modify them in different positions. At the end of the show, the system can automatically generate modification suggestions.

Information science is the basic premise of synthetic virtual reality. Virtual reality needs to solve the following three main problems. There are technologies that confuse the real with the false. That is, how to synthesize the input information consistent with the actual existence for the observer's sensory organs, that is, how to produce the same vision, touch, smell, and so on as the real environment. Interaction. How do observers actively operate virtual reality to realize different viewpoints and higher-level sensory information? In fact, that is, how can we see more like, listen more truly, and so on. Self-regulatory reality. How can the perceiver get a vivid sense of reality without being aware of his actions and behaviors? Here, observers, sensors, computer simulation system, and display system constitute an interactive closed-loop process.

\section{Clothing Model Constructions}

In order to realize the virtual simulation of children's clothing, the design and modeling of individual clothing are needed. In this paper, LectraCAD and Clo3D are used to establish individual clothing model. According to the selected clothing design style, the specific steps are as follows:

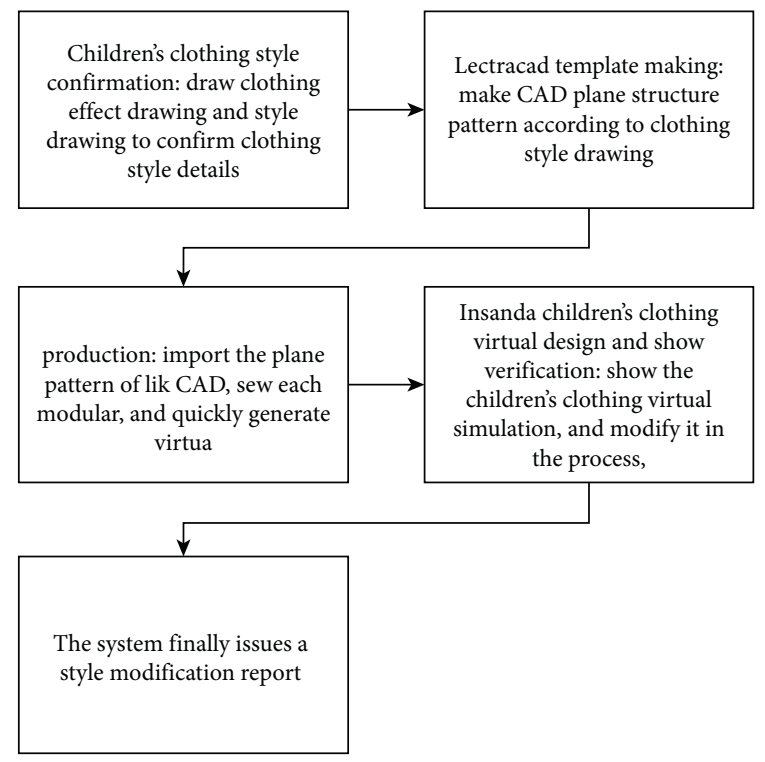

FIgURE 2: Technical route.

(1) Because the bright spots of this style are the intangible cultural heritage pattern on the chest and the lace layout under the armpit, HP fabric scanner is used to scan all fabrics.

(2) According to the children's clothing style drawing, Lectra clothing CAD divided them into top clothing and bottom clothing. The front and rear pieces are divided into $6 \mathrm{CAD}$ pattern modules, namely, top pieces X2; Lower hem X1; Underarm decoration X1; Collar piece X1; and Patch X1. It contains the point line structure in the $2 \mathrm{D}$ view, and the structure line and edge line of the garment piece.

(3) The. DXL file of LectraCAD is imported into Clo3D; then, the children's wear model is selected and the body data of the virtual model is set as the 6-year-old standard through the model editor. The clothing engineering center of Xi'an University of Engineering uses France's ET three-dimensional human body scanner to obtain the three-dimensional digital 
body map of children aged 3-6 years, which can be directly imported and used [19].

(4) The garment template can be adjusted in the Clo3D software. By adjusting the two-dimensional version of the garment appropriately, the corresponding garment 3D model can match the 3D model of human body. Moreover, several auxiliary matching points are added to make the two-dimensional garment pieces correspond to the virtual mannequin, and thereby improving the association between them.

(5) The selected templates are sewed together with sewing thread. To ensure the correct direction and same length of sewing thread, attention should be paid to the cutting. When sewing, the samples should be arranged on the three-dimensional interface. And, functions such as arrangement points should be used to keep the plates beside the model's body so as to correspond to clothes.

(6) When the above steps are finished, the whole project file is generated and imported into Insanda children's clothing virtual design and show virtual simulation software.

In addition, the defects of Clo3D software include: 1 . Fabrics. Clothing design pays great attention to fabrics. Clo3D has too few fabrics and takes time to adjust itself. Taking photos with a camera to make patterns and textures can only do diffuse mapping. 2. The default model is too ugly and needs to import another 3D model, which requires designers to have the skills of 3D software other than Clo3D.

\section{Implementation of Insanda Children's Clothing Virtual Design and Show Virtual Simulation Software}

5.1. UE4 Interactive Virtual Development Environment. Unreal engine UE4 is a game development engine launched by Epic Games. Compared with other engines, unreal engine is not only efficient and versatile but also can directly preview the development effect. With "what you see is what you get" as the design concept, unreal engine can realize some functions that 3D Studio MAX and Maya do not have, and apply these functions in game development. In the visual editing window, game developers can directly render all the characters in the game in real time. And, this real-time rendering also has dynamic light and shadow effects. UE4 is more novel than other development software, but now there is no virtual simulation software using UE4 in the clothing field. At present, unity3d is most commonly used in the field of clothing simulation and virtual fitting [17]. However, UE4 has stronger virtual integration ability and is more supportive of the use of VR helmets. Therefore, UE4 offers a good future for development. Our team collaborates with America's UE4 company for developing an interactive virtual simulation platform.

UE4 supports the setting of physical collision attributes. The rigid object collision system allows operating players to make full use of the object collision, character animation collision, complex and real vehicles, and object explosion in the game for entertainment. All rendered objects and models can be set with dynamic attributes, including friction.

5.2. Introduction to Software Development. Insanda children's clothing virtual design and show virtual simulation software has functions such as children's show, design modification, and design evaluation, and can issue style modification report with the help of human-computer interaction and machine learning. It supports $3 \mathrm{D}$ full-window virtual simulation on Windows 7 , Windows 10 , Vista, and other Microsoft operating platforms.

The virtual simulation software has strong object-oriented function and $3 \mathrm{D}$ animation function. The simulation model is displayed realistically in the form of image rendering, that is, simulation operation. So, the effect and comfort evaluation of children's show are close to the real feeling to the greatest extent. It is mainly based on the following system architecture, as shown in Figure 3.

First, the machine learning of the virtual simulation software extracts attribute data related to the preset tag; second, the preset tag is calibrated according to the attribute data; third, the attribute data and the preset tag are set as the training set. Finally, supervised learning is performed based on the support vector regression algorithm and the regression curve of the preset tag is obtained; the regression curve is used to predict the value of the preset label according to the attribute data, thereby realizing the simulation of children's clothing fashion show scoring. Through the support vector regression algorithm in machine learning, the attribute data and labels of children's clothing show are trained. In this way, the simulation and test of virtual children's clothing on the simulation platform can be realized and clothing structure comfort can be improved.

The children's clothing virtual simulation system in this paper consists of five main functional modules (as shown in Figure 4), namely, Garment 3D model acquisition, fashion show generation, user operation interaction, garment design annotation, and modification report generation. The three-dimensional model of clothing uses the general $3 \mathrm{~d}$ graphics format, which includes the geometric model of $3 \mathrm{~d}$ mesh of each component of clothing and the texture map of the clothing fabric. The system imports the $3 \mathrm{~d}$ model through UE4 platform and uses Clo3D clothing modeling software for modeling. In order to conduct the design and model of individual clothing, it is necessary to establish special 3D virtual models of all individual clothing patterns and styles.

5.3. Experimental Effect of the Virtual Simulation System. Insanda children's clothing virtual design and show software can realize functions such as scene design and switching, model loading, lighting and shadow adjustment, path adjustment, display interface, and interactive operation under UE4 development environment. And, C\# script language is used to realize system development. The system home page 


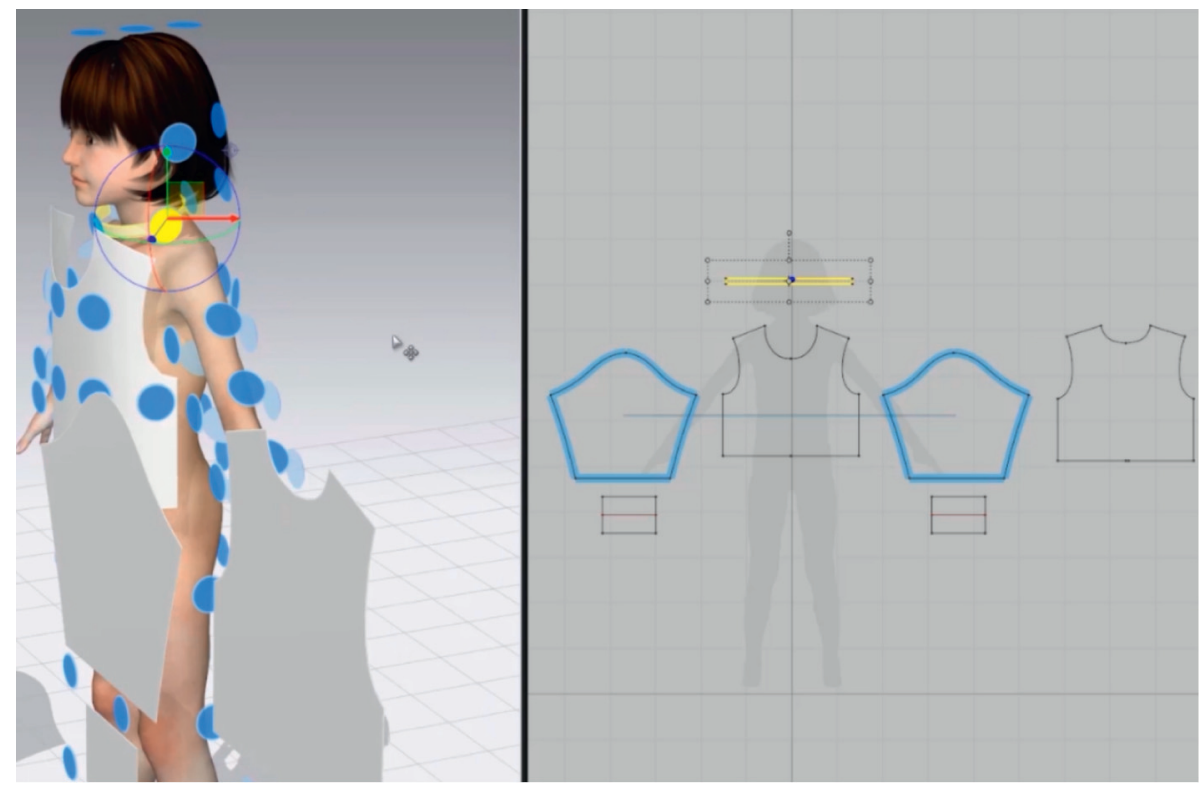

FIgURE 3: Clo3D modular virtual simulation.
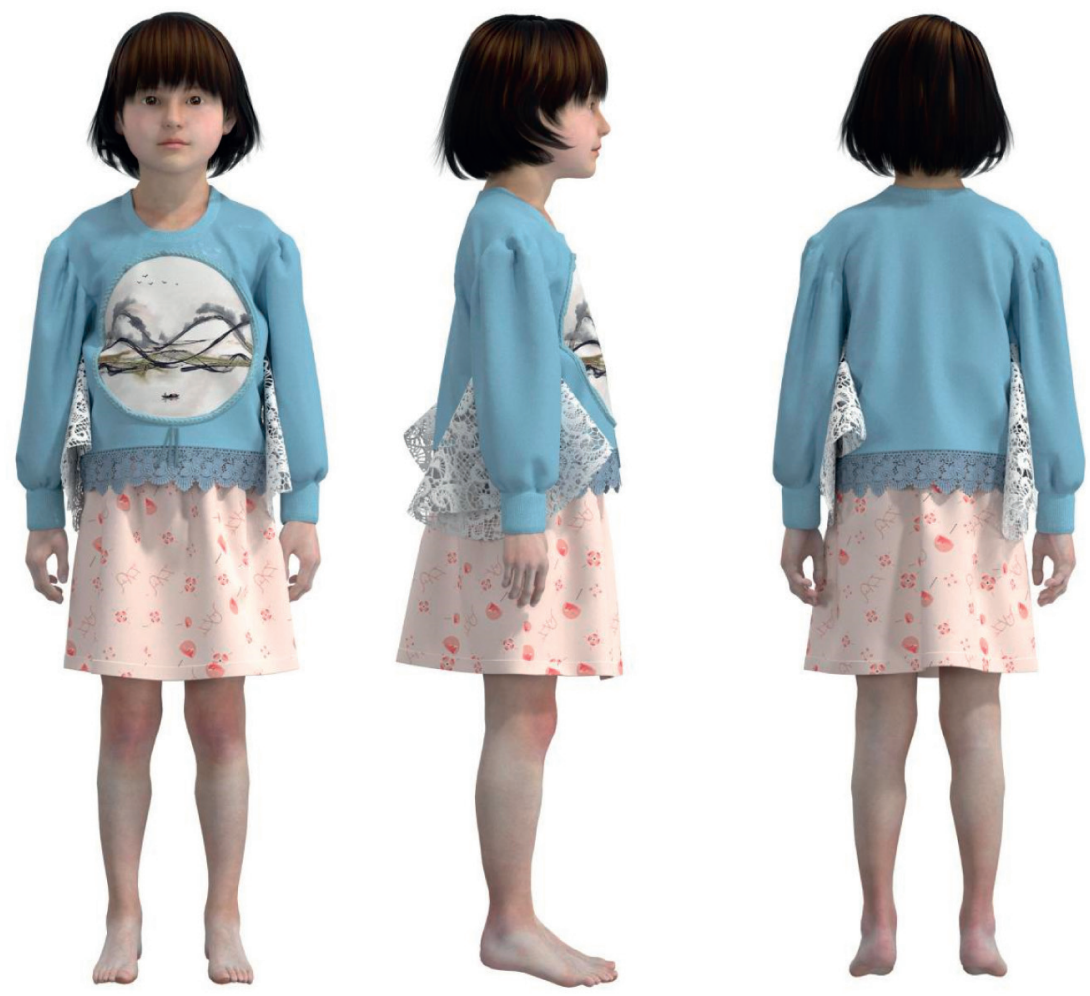

Figure 4: Effect diagram after CLO3d virtual simulation.

contains buttons such as "load model," "select $t$ station," "Select Action," "modify Annotation," "generate report," and "exit the system":

(1) Load model to realize the loading addition of children's $3 \mathrm{~d}$ mannequin and clothing model.
(2) Select a 3d background that conforms to the style. Users can wear VR helmets for synchronous operation, making it more immersive.

(3) Choose the way of children's show, including normal show or dynamic show with rhythm and sports effect. 


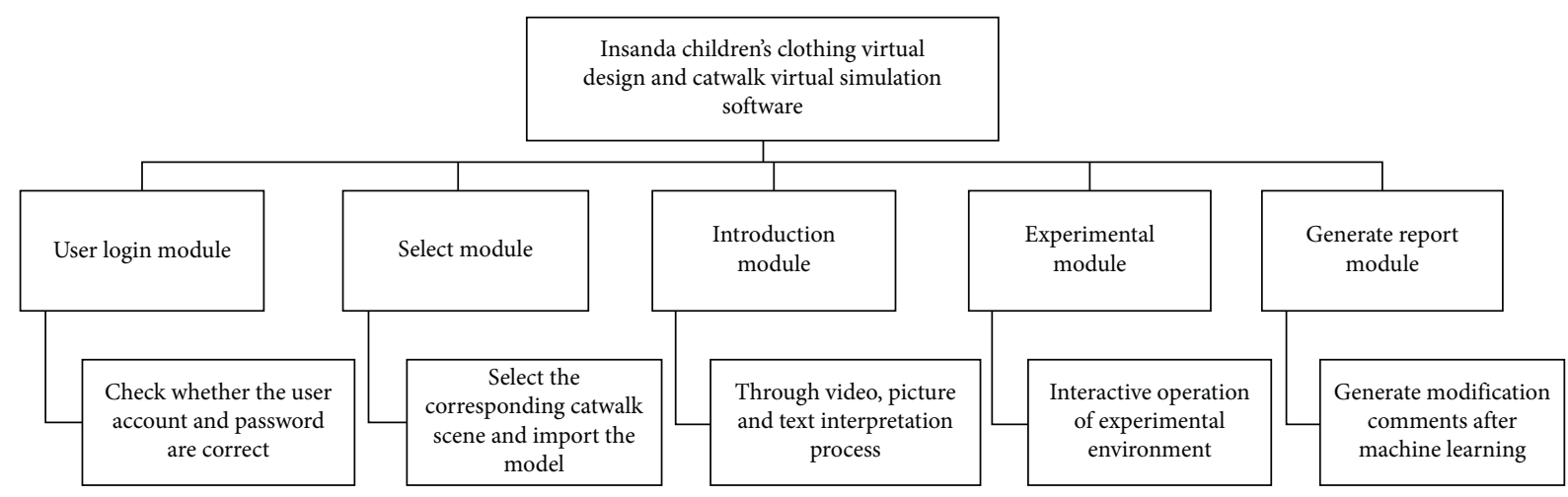

FIGURE 5: System architecture.

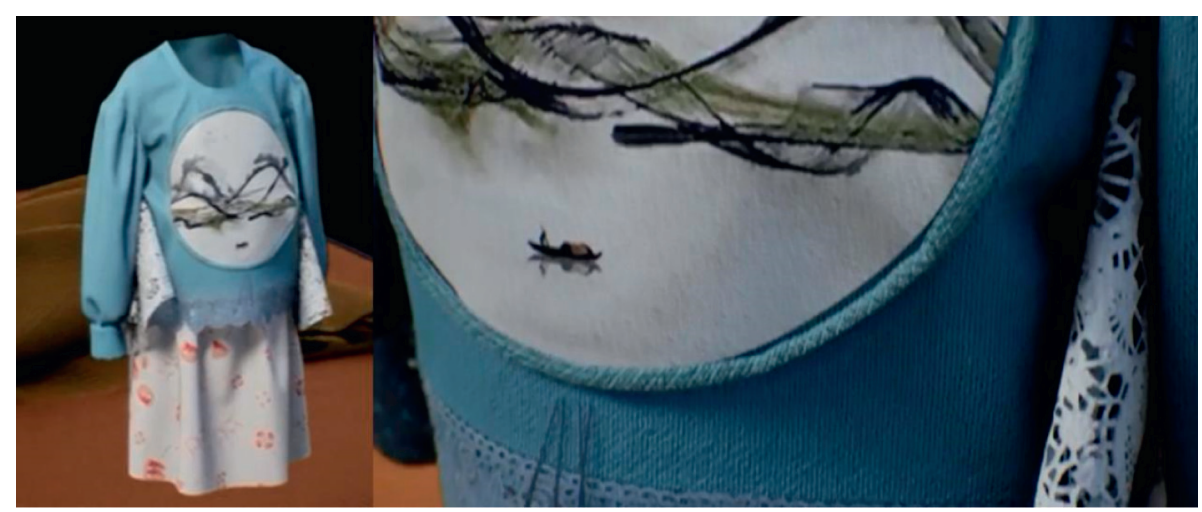

FIgURE 6: Visual effect in Insanda children's virtual design and walk show VR.

(4) During the show, you can watch the details of children's clothes, pull the fabric, and feel the drape of the fabric. At the same time, the tags can be selected according to the hanging window instructions. The interaction mode realizes the transformation of observation angle mainly through keyboard and mouse (as shown in Figures 5-7).

(5) After collecting enough labels, the system generates a modification suggestion for children's clothing through in-depth machine learning, and then exits the simulation.

\section{Prospect and Shortcoming}

This paper is to solve the problems that the professional nature of children's clothing models is vague and designers lack fitting comparison.

At the same time, the paper also aims to improve the efficiency of designers and fashion buyers, follow the trend of sustainable development, and minimize the waste of human resources, material, and time. A children's clothing model is established by using clothing CAD software, and its main parts are modularized. With the help of $3 \mathrm{~d}$ virtual display software, the body size of the virtual model is set as the standard parameter, and the effect of the virtual model wearing children's clothing composed of modular parts is displayed. Finally, the software suitable for children's clothing simulation is developed, which is used for showing

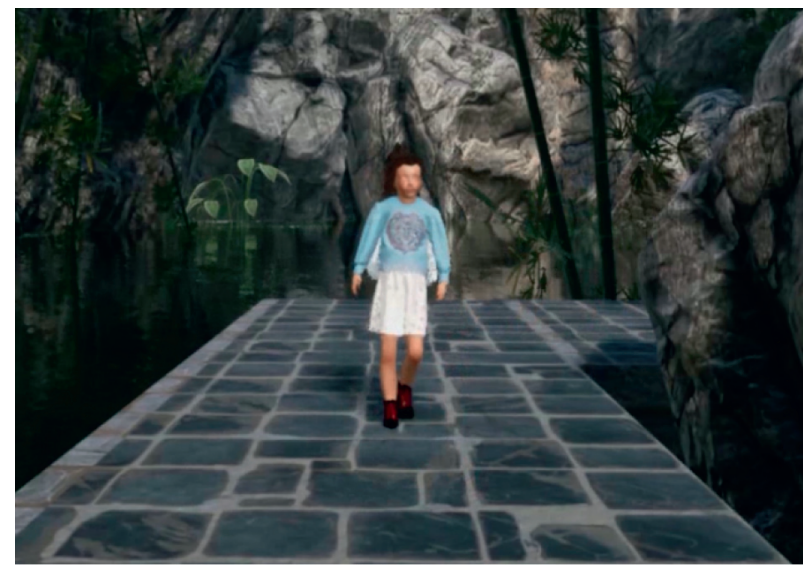

FIGURE 7: Virtual design of Insanda children's clothing and virtual show effect.

and modifying the views. The software platform is based on a single module to realize design, structure build, multimodule conversion, and hardware interaction. By constructing the venue for children's show and display simulation, the dynamic model of simulated children's clothing and clothes is established. Then UE4 software is used to optimize the $3 \mathrm{~d}$ scene and model, and configure the simulated children's clothing design and matching recommendation in real time. Through VR roaming, the fitting effect between children's clothing version and children's 
bodies of different ages can be observed, and adjustments are made timely to achieve the best effect on the overall design and comfort of children's clothing.

There are two points that have not been realized in this paper. One is that the simulation of various big action motion states of children's clothing. The second point is that children's clothing show generates motion paths, which can connect and capture motion data in the field of immersive clothing. Let another person put on a sensor, and then record the movement of this group of marked points with a motion capture system. Finally, immerse and operate in real time in the VR environment through data processing and data analysis; therefore, the two points are also the directions for further research.

\section{Conclusion}

In view of the inconvenient display of children's clothes and the lack of experience of designers in modifying model clothes, this paper carries out rapid design through corresponding software, which can save a lot of time on the one hand. On the other hand, it effectively verifies the effectiveness and rationality of the strategy proposed in this paper. Thus, it provides some reference ideas for the followup research.

\section{Data Availability}

The data underlying the results presented in the study are included within the manuscript.

\section{Conflicts of Interest}

The authors declare no conflicts of interest.

\section{Authors' Contributions}

All authors have seen the manuscript and approved the manuscript for submission.

\section{References}

[1] B. Tudjarov, A. Bachvarov, and I. Boyadjiev, "Web virtual reality for product customization," Advances in Production Engineering and Management, vol. 1, no. 4, pp. 25-34, 2009.

[2] B. J. Pine, Mass Customization: The New Frontier in Business Competition, Harvard Business School Press, Boston, MA, USA, 1993.

[3] David, Designing Interactive Systems, Pearson Education Limited, London, UK, 2005.

[4] X.-F. Zhang and R.-Q. Huang, "Virtual display design and evaluation of clothing: a design process support system," International Journal of Technology and Design Education, vol. 24, no. 2, pp. 223-240, 2014.

[5] X. H. Liu and Y. W. Wu, "A 3D display system for cloth online virtual fitting room," in Proceedings of the World Congress on Computer Science and Information Engineering, pp. 14-18, Los Angeles, CA, USA, March 2009.

[6] F. Yan, L. Yang, and H. Li, "A fabric display system in virtual reality environments based on web," in Proceedings of the $3 \mathrm{rd}$ IEEE International Con-Ference on Computer Science and Information Technology, Chengdu, China, July 2010.
[7] Bozman, The Disappearance of Childhood, Guangxi Normal University Press, Guangxi, China, 2009.

[8] Kirk, Women's Lives: Multicultural Perspectives, Mayfield Publishing Company, Mountain View, CA, USA, 1998.

[9] C. Mihaly, Beyond Boredom and Anxiety, Jossey-Bass, San Francisco, CA, USA, 2000.

[10] I. Santesteban, M. A. Otaduy, and D. Casas, "Learning-based animation of clothing for virtual try-on," Computer Graphics Forum, vol. 38, no. 2, pp. 355-366, 2019.

[11] J. Li, G. Daviet, and R. Narain, "An implicit frictional contact solver for adaptive cloth simulation," ACM Transactions on Graphics, vol. 37, no. 4, pp. 1-15, 2018.

[12] T. Yu, Z. R. Zheng, and Y. Zhong, "Simul cap: single-view human performance capture with cloth simulation," https:// arxiv.org/abs/1903.06323.

[13] C. Y. Huang, "Analysis on technology framework of 3D virtual fitting based on network," Applied Mechanics and Materials, vol. 543-547, pp. 2961-2964, 2014.

[14] H. Theisel, F. Weinkanud, and H.-C. Hege, "Saddle connectors-an approach to cisualizing the topological skeleton of complex 3D vector fields," 2000.

[15] Z. Pan, Q. Ji, M. Zhang, Y. Li, and L. Mei, "Simulating pattern design and layout for group calisthenics and eurhythmics," Simulation \& Gaming, vol. 37, no. 4, pp. 423-437, 2006.

[16] L. Xu and Z. Geng, "Design and implementation of virtual clothing catwalk System based on unity," Journal of Beijing Institute of Clothing, vol. 39, no. 3, pp. 66-72, 2019.

[17] R. Crespo, R. García, and S. Quiroz, "Virtual reality application for simulation and off-line programming of the mitsubishi movemaster RV-M1 robot integrated with the oculus rift to improve students training," Procedia Computer Science, vol. 75, pp. 107-112, 2015.

[18] N. Nguyeny, N. Wheatland, and D. Brown, "Performance capture with physical interaction," in Proceedings of the Eurographics/ACM SIGGRAPH Symposium on Computer Animation, vol. 10, pp. 189-195, Madrid: Spain, October 2010.

[19] D. Helbing and I. Farks, "VICSEK T simulating dunamical features of escape panic," Letters to Nature, pp. 407-490, 2000. 